\title{
A sensitivity analysis of SCM dynamic parameters on improving the engine vibration and power
}

\author{
Wenlin Hua \\ School of Mechanical and Electrical Engineering, Hubei Polytechnic University, Huangshi, 435003, China \\ Hubei Key Laboratory of Intelligent Conveying Technology and Device, Hubei Polytechnic University, \\ Huangshi, 435003, China \\ E-mail: 648310145@qq.com
}

Received 19 November 2020; received in revised form 1 December 2020; accepted 7 December 2020 DOI https://doi.org/10.21595/vp.2020.21809

Check for updates

Copyright $(\mathbb{C} 2021$ Wenlin Hua. This is an open access article distributed under the Creative Commons Attribution License, which permits unrestricted use, distribution, and reproduction in any medium, provided the original work is properly cited.

\begin{abstract}
To improve the vibration and power of the engine, a sensitivity analysis of the operating parameters as well as the eccentricity between crankshaft centre and cylinder centre of the slider-crank-mechanism (SCM) are proposed and researched based on the SCM's dynamics model and the experimental data of the cylinder pressure in the internal combustion engine. An algorithm program developed in MATLAB environment is then applied to compute the dynamic equations of the SCM. The numerical simulation results show that the eccentricity $e$, connecting rod length $l$, and crankshaft radius $r$ are substantially affected the vibration and power of the engine. Particularly, with $e=-0.01$, the connecting rod length of $\{1.0-1.2\} \times l$, and crankshaft radius of $\{1.0-1.2\} \times r$ could improve the vibration and increase the engine power.
\end{abstract}

Keywords: internal combustion engine, slider-crank mechanism, engine vibration and power.

\section{Introduction}

Increasing engine power and reducing fuel had been one of the main concerns of the internal combustion engine (ICE) manufacturers. In order to improve the power of the ICE, the effect of the engine cooling system, combustion chamber pressure, and combustion mixture composition were researched and optimized $[1,2]$. The variable valve timing-intelligent, fuel injection system, and engine turbocharger had been developed and applied for the engine to increase its power [2,3]. The research results indicated that the ICE's power and its fuel economy had been substantially improved. However, the level of the noise, vibration as well as friction of the ICE were still high [4-6]. This was also due to a part of the effect of the piston skirt and rings against the cylinder bore in the motion process and the relative motion of the slider-crank mechanism (SCM) [7-9]. In order to improve the vibration level and engine power, the design parameters of the ICE such as inertial forces of the piston and mass of the piston and SCM are studied to decrease the horizontal impact force of the piston on the cylinder bore [5, 10-12]. The lubrication studies of the surface pairs of the piston and cylinder, and journal bearings of the SCM to reduce their friction forces had been done [13-15]. The result of the friction power loss was then improved. However, the above research had also indicated that the friction power loss and vibration of the engine had been strongly affected by the dynamic loads acting on the SCM and cylinder in a working cycle of the engine. Thus, the reasonable parameters of the SCM can reduce the horizontal impact force and improve the power and vibration of the ICE.

To reduce the vibration and improve the engine power, the effect of the lumped parameters of the SCM and the eccentricity between crankshaft centre and cylinder centre are researched based on the SCM dynamics model and the experimental pressure data of the ICE. An algorithm program developed in MATLAB environment is applied to solve the dynamic equations of the SCM. The study goal is to evaluate the effect of the structure parameters on reducing the vibration and friction force of piston-cylinder and increasing the engine power. 


\section{Lumped parameter model of the SCM}

In order to evaluate the effect of the lumped parameters of the SCM and the eccentricity between crankshaft centre and cylinder centre on the improvement the vibration and the engine power, the lumped parameters of the SCM with different eccentricities of $e>0, e=0$, and $e<0$ are established to simulate and evaluate the results, as shown in Fig. 1(a), where $\omega, l$, and $r$ are defined as the angular velocity, the connecting rod length, and the radius of the crankshaft, respectively. $z_{p}$ is the piston displacement in the cylinder. $P$ is the combustion gas pressure impacting on the piston peak. $F_{i p}$ is the inertial force of the lumped mass of the piston-small rod end. $F_{1}$ and $F_{2}$ are the impacting forces of the piston on the connecting rod and cylinder wall while $F_{3}$ and $F_{4}$ are the impacting forces of the connecting rod on the crankpin. $F_{i c}$ the centrifugal inertial force of the big rod end of the connecting rod and $T$ is the engine torque.
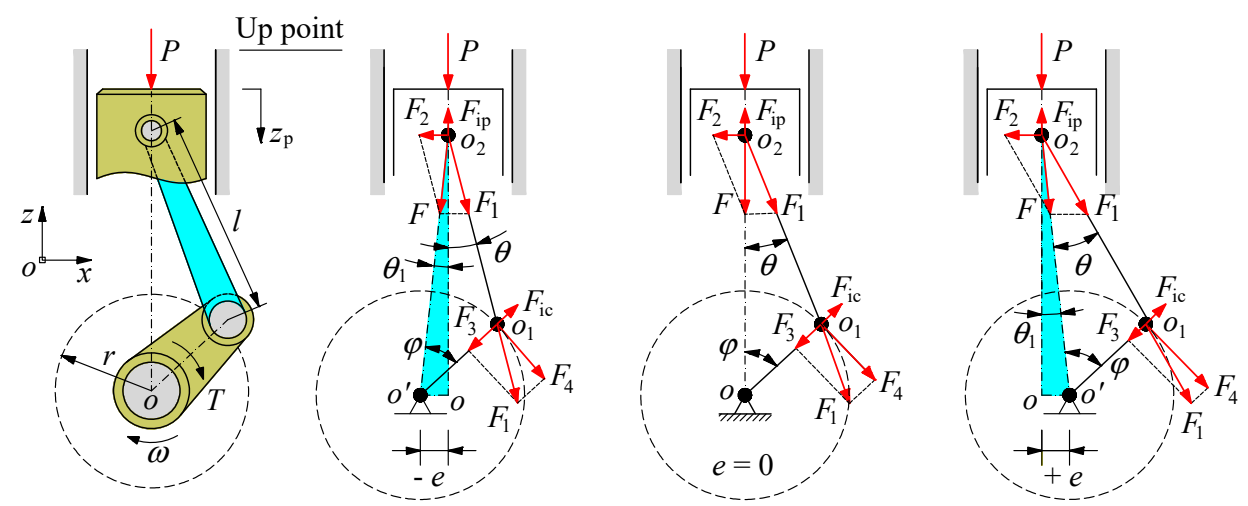

Fig. 1. The lumped parameter model of the SCM with different eccentricities of $e$

Based on the lumped parameters of the SCM in Fig. 1(a) with three different cases of the value $e$, the dynamic force equations of the SCM are then determined as follows.

(1) The dynamic force equations of the SCM with $+e$ : The stroke of the piston and its acceleration in the $z$-direction is determined by:

$z_{p}=(l+r) \cos \theta_{1}-l \cos \left(\theta+\theta_{1}\right)-r \cos \left(\varphi-\theta_{1}\right)$,

$a_{p}=\omega^{2}\left[l \cos \left(\theta+\theta_{1}\right)+r \cos \left(\varphi-\theta_{1}\right)\right]$.

The dynamic force equations of the SCM and connecting rod $\left\{P, F_{i p}, F_{1-4}\right\}$ are calculated by:

$$
\begin{aligned}
& P=p \times \pi R^{2}, \quad F_{i p}=-m a_{p}=-m \omega^{2}\left[l \cos \left(\theta+\theta_{1}\right)+r \cos \left(\varphi-\theta_{1}\right)\right], \\
& F=\frac{P+F_{i p}}{\cos \theta_{1}}, \quad F_{2}=\frac{F \sin \theta}{\sin \left(\theta+\theta_{1}\right)}, \quad F_{4}=\frac{F \sin \theta \sin \theta_{1}}{\sin (\varphi+\theta)} .
\end{aligned}
$$

By transforming Eqs. (1) and (2), the friction force $F_{f}$ and torque $T$ are determined by:

$$
F_{f}=\mu \times F_{2}, \quad T=r \times F_{4} .
$$

(2) The dynamic force equations of the SCM with $e=0$ : In the case of the centre of crankshaft coinciding with the cylinder centre, the stroke and acceleration of the piston in the $z$-direction is written as follows:

$z_{p}=r+l-l \cos \theta-r \cos \varphi, \quad a_{p}=\omega^{2}(l \cos \theta+r \cos \varphi)$. 
The dynamic force equations of the SCM and connecting rod $\left\{P, F_{i p}, F_{1-4}\right\}$ are calculated by:

$$
F_{i p}=-m a_{p}, \quad F=P+F_{i p}, \quad F_{2}=F \tan \theta, \quad F_{4}=\frac{F \sin (\varphi+\theta)}{\cos \theta} .
$$

Similarly, by transforming Eqs. (4) and (5), the friction force $F_{f}$ and torque $T$ are:

$F_{f}=\mu \times F_{2}, \quad T=r \times F_{4}$.

(3) The dynamic force equations of the SCM with $-e$ : The stroke and acceleration of the piston in the $z$-direction is determined as follows:

$z_{p}=(l+r) \cos \theta_{1}-l \cos \left(\theta-\theta_{1}\right)-r \cos \left(\varphi+\theta_{1}\right)$,

$a_{p}=\omega^{2}\left[l \cos \left(\theta-\theta_{1}\right)+r \cos \left(\varphi+\theta_{1}\right)\right]$.

Therefore, the dynamic force equations of the SCM and connecting rod are calculated by:

$F_{\text {ip }}=-m a_{p}=-m \omega^{2}\left[l \cos \left(\theta-\theta_{1}\right)+r \cos \left(\varphi+\theta_{1}\right)\right]$,

$F=\frac{P+F_{i p}}{\cos \theta_{1}}, \quad F_{1}=\frac{F \sin \theta_{1}}{\cos \theta}, \quad F_{2}=\frac{F_{1} \sin \left(\theta+\theta_{1}\right)}{\cos \theta_{1}}, \quad F_{4}=F_{1} \sin (\varphi+\theta)$.

Similarly, by transforming Eqs. (7) and (8), the friction force $F_{f}$ and torque $T$ are given by:

$F_{f}=\mu \times F_{2}, \quad T=r \times F_{4}$,

where $\mu$ is the friction coefficient between two surface contacts of the piston and cylinder. In the previous researches of the lubrication of the piston-cylinder or journal crankpin $[7,14,15]$, the main lubrication of the piston-cylinder is the mixed lubrication region, and its friction coefficient is $\mu$ from 0.001 to 0.0015 . Thus, $\mu=0.001$ is chosen in this study to evaluate the friction power loss of the engine.

Based on the dynamic force equations of the SCM, the piston acceleration $a_{p}$, friction force $F_{f}$, and torque $T$ are then applied to evaluate the vibration and improve the engine power.

\section{Numerical simulation and result analysis}

\subsection{Effect of the eccentricity between crankshaft centre and cylinder centre}

In order to evaluate the effect of the eccentricity $e$ on the vibration and power of the engine, the lumped parameters of the SCM listed in Table 1 and the experimental data of cylinder pressure at the engine speed of $2000 \mathrm{rpm}$ plotted in Fig. 2 are applied for the simulation process. A value range of $e=\{-0.02,-0.01,0,+0.01,+0.02\}$ is then simulated, respectively. The results of the displacement, acceleration, friction force, and torque are shown in Fig. 3, respectively.

Fig. 3(a) shows that the piston displacement is not affected by the values of $e$. This is due to the change of $e$ being very small, thus, the piston displacement in the vertical direction $z$ is not changed. This result is found in Ref. [5]. However, the piston acceleration $a_{p}$ in Fig. 3(b) is strongly affected under the various values of $e$. With $e=0$, the $a_{p}$ is quite low, this means that the engine vibration is also quite small. On the contrary, with both the values of $\pm e$, the $a_{p}$ is quickly increased, thus the engine vibration is also increased. This may be due to the influence of the asymmetry of the SCM structure. Additionally, the $a_{p}$ with $e= \pm 0.02$ is higher than the $a_{p}$ with $e= \pm 0.01$, and the $a_{p}$ with $+e$ is also higher than the $a_{p}$ with $-e$. Therefore, it can be concluded that with the increase of the $e$ or with the use of $+e$, the engine vibration is substantially 
increased. Observing both Figs. 3(c-d), the friction force $F_{f}$ and engine torque $T$ are increased with $e=+0.01$ and +0.02 . Thus, the engine power can be slightly increased but the friction power loss is higher. Conversely, with $e=-0.01$ and -0.02 , both the $F_{f}$ and $T$ are reduced compared to the $e=0$. Especially with $e=-0.01$, the $T$ is insignificantly reduced and thus the engine power is also insignificantly affected, however, the maximum $F_{f}$ is remarkably reduced, thus, the friction power loss is also reduced. Based on the simulation and analysis results, it can be concluded that the $e=-0.01$ can substantially improve the engine power.

Table 1. The SCM operation parameters [14]

\begin{tabular}{|c|c|c|c|}
\hline Parameters & Values & Parameters & Values \\
\hline$l / \mathrm{mm}$ & 129.5 & $m b r / \mathrm{kg}$ & 0.250 \\
\hline$r / \mathrm{mm}$ & 40 & $\mu$ & 0.001 \\
\hline$m p / \mathrm{kg}$ & 0.264 & $R / \mathrm{mm}$ & 25 \\
\hline$m / \mathrm{kg}$ & 0.45 & $\varphi /{ }^{\circ}$ & $0-720$ \\
\hline
\end{tabular}

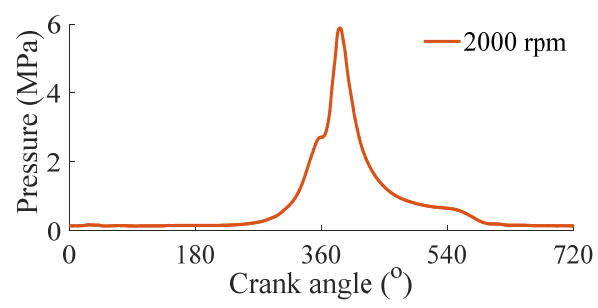

Fig. 2. The combustion gas pressure [7]

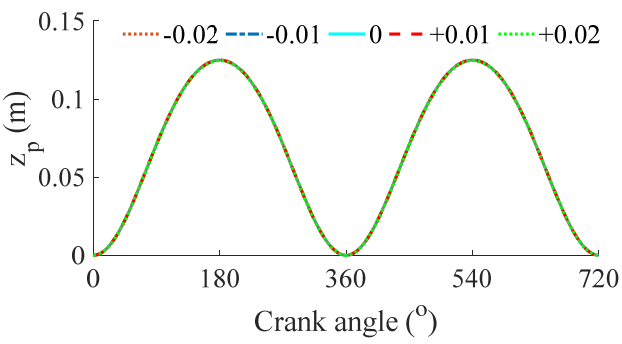

a) Piston displacement

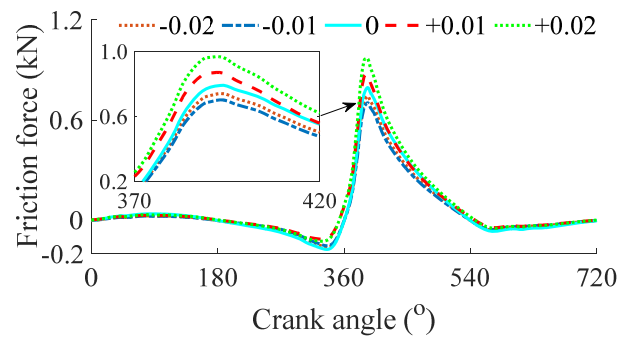

c) Friction force between piston-cylinder

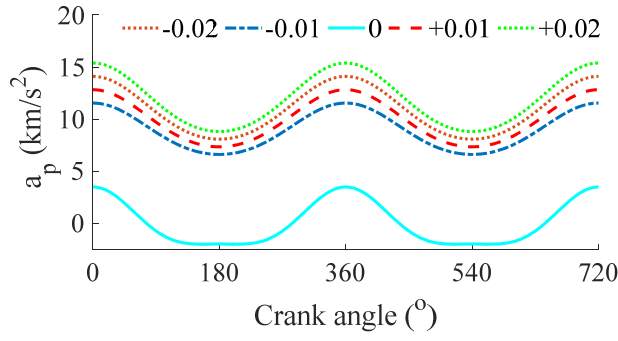

b) Piston acceleration

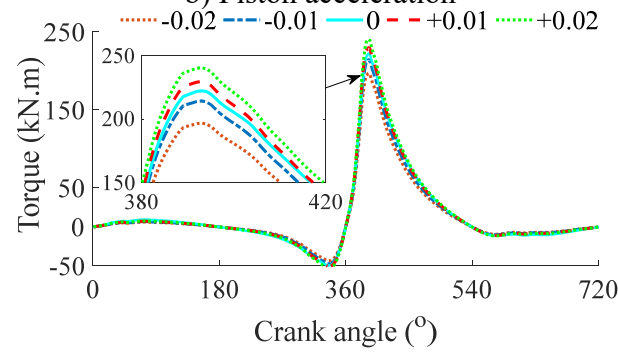

d) Engine torque

Fig. 3. Effect of the eccentricities $e$ on vibration and engine power

\subsection{Effect of the dynamic parameters of the SCM}

Both the lumped parameters of the connecting rod length $\{0.6,0.8,1.0,1.2\} \times l$ and the radius of the crankshaft $\{0.6,0.8,1.0,1.2\} \times r$ of the SCM which can affect the engine vibration and power are also simulated and plotted in Fig. 4 and Fig. 5, respectively.

With the change of the $l$ : When the $l$ is reduced by $\{0.6 \div 0.8\} \times l$, although the engine torque in Fig. 4(c) is slightly increased with $0.6 \times l$ and $0.8 \times l$, however both the $a_{p}$ and maximum $F_{f}$ in Figs. $4(\mathrm{a}-\mathrm{b})$ are greatly increased, especially $0.6 \times l$, thus, both the engine vibration and friction power loss are strongly increased. When the $l$ is increased by $\{1.0$ and 1.2$\} \times l$, both the $a_{p}$ and maximum $F_{f}$ are reduced, thus, the engine vibration and friction power loss are improved. However, the increase of the $l$ can increase the engine height and affect the vehicle's structure.

With the change of the $r$ : Similarly, when the $r$ is reduced by $\{0.6$ and 0.8$\} \times r$, both the $a_{p}$ 
and maximum $F_{f}$ in Figs. 5(a-b) are greatly reduced, thus, the engine vibration and friction power loss are significantly improved. However, the engine torque $T$ in Fig. 5(c) is also strongly reduced, thus it directly affects the engine power, particularly at $0.6 \times r$. On the contrary, when the $r$ is increased by $\{1.0$ and 1.2$\} \times r$, the $T$ is strongly increased, thus the engine power is also increased. However, both the $a_{p}$ and maximum $F_{f}$ are also increased. The study results of the effects of the $l$ and $r$ in this study are also similar as the previous results found in Refs. [7, 9]. Therefore, it is very difficult to simultaneously satisfy two conditions of the reduction of the engine vibration and friction power loss and increase of the engine torque. To solve this issue, the optimization of the lumped parameters of the SCM is necessary.

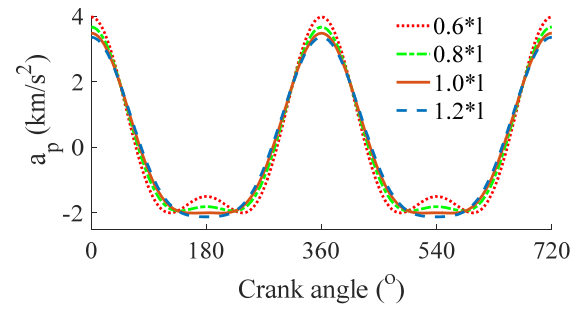

a) Piston acceleration

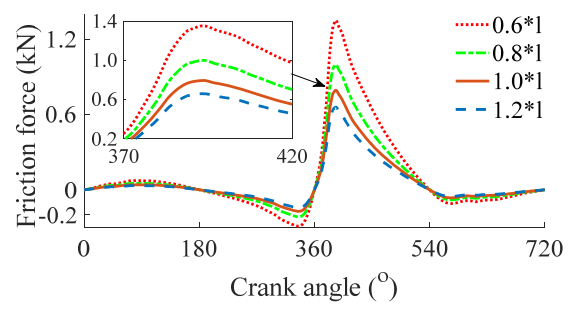

b) Friction force between piston-cylinder

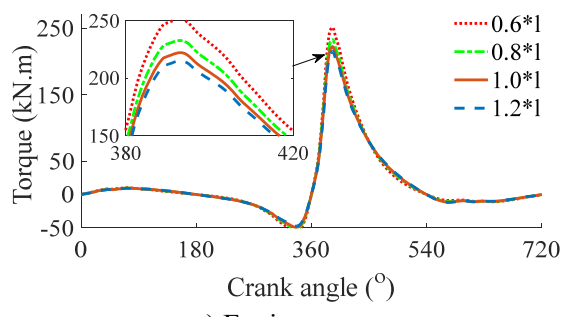

c) Engine torque

Fig. 4. Effect of the connecting rod length $l$

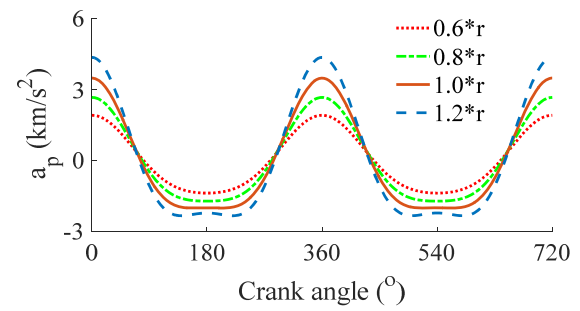

a) Piston acceleration

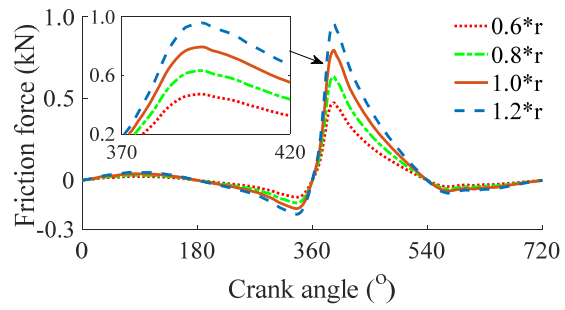

b) Friction force between piston-cylinder

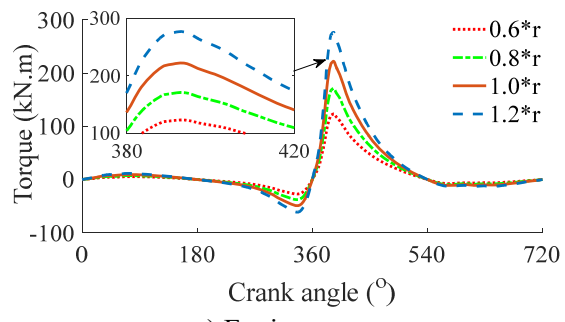

c) Engine torque

Fig. 5. Effect of the crankshaft radius $r$

\section{Conclusions}

Based on the SCM dynamics model and the experimental data of the cylinder pressure in the ICE, the effect of the lumped parameters of the SCM and the eccentricity between crankshaft centre and cylinder centre on improving the vibration and power of the engine is researched. The research results can be concluded as follows:

1) The eccentricity between the crankshaft centre and cylinder centre significantly affects the vibration and power of the engine. Especially with $e=-0.01$, the piston acceleration is slightly increased, however, the friction power loss is significantly reduced, therefore, the engine power is also improved.

2) Under the influence of the connecting rod length and the radius of the crankshaft of the $\mathrm{SCM}$, the vibration and power of the engine are greatly influenced. All the vibration, friction power loss, and engine torque are increased with the increase of both the $l$ and $r$, and vice versa. The vibration and power of the engine can be improved by using the values of $\{1.0-1.2\} \times l$ and 
$\{1.0-1.2\} \times r$, therefore, the range of these values should be concerned for the design and optimization of the SCM of the ICE.

\section{Acknowledgements}

This research was supported by Teaching and Research Project of Hubei Polytechnic University (No. 2020A05).

\section{References}

[1] Arya K. H., Soheil R., et al. An intelligent cooling system and control model for improved engine thermal management. Applied Thermal Engineering, Vol. 128, 2018, p. 253-263.

[2] Choi Y. H., Lee J. T., Jang J. W., Park S. W. Effects of fuel-injection systems on particle emission characteristics of gasoline vehicles. Atmospheric Environment, Vol. 217, 2019, p. 116941.

[3] Chiong M. S., Rajoo S., et al. Engine turbocharger performance prediction: One-dimensional modeling of a twin entry turbine. Energy Conversion and Management, Vol. 57, 2012, p. 68-78.

[4] Tung S. C., Mcmillan M. L. Automotive tribology overview of current advances and challenges for the future. Tribology International, Vol. 37, 2004, p. 517-536.

[5] Cho S. H., Ahn S. T., Kim Y. H. A simple model to estimate the impact force induced by piston slap. Journal of Sound and Vibration, Vol. 255, 2002, p. 229-242.

[6] He Z. P., Gong W. Q., et al. NVH and reliability analyses of the engine with different interaction models between the crankshaft and bearing. Applied Acoustics, Vol. 101, 2016, p. 185-200.

[7] Zhao B., Dai X. D., Zhang Z. N., Xie Y. B. A new numerical method for piston dynamics and lubrication analysis. Tribology International, Vol. 94, 2016, p. 395-408.

[8] Lia Y. Y., et al. Dynamic analysis and optimization design of a planar slider-crank mechanism with flexible components and two clearance joints, Mech. Mach. Theory, Vol. 99, 2016, p. 37-57.

[9] Meng X., Ning L., Xie Y., Wong V. W. Effects of the connecting-rod-related design parameters on the piston dynamics and the skirt-liner lubrication. Proceedings of the Institution of Mechanical Engineers, Part D: Journal of Automobile Engineering, Vol. 227, Issue 6, 2012, p. 885-898.

[10] Liu K., Xie Y., Gui C. A comprehensive study of the friction and dynamic motion of the piston assembly. Proceedings of the Institution of Mechanical Engineers, Part J: Journal of Engineering Tribology, Vol. 212, 1998, p. 221-226.

[11] Mansouri S. H., Wong V. W. Effects of piston design parameters on piston secondary motion and skirt-liner friction. Proceedings of the Institution of Mechanical Engineers, Part J: Journal of Engineering Tribology, Vol. 219, 2005, p. 435-449.

[12] Guzzomi A. L., Hesterman D. C., Stone B. J. Variable inertia effects of an engine including piston friction and a crank or gudgeon pin offset. Journal of Automobile Engineering, Vol. 222, 2008, p. 397-414.

[13] Wu Z., Nguyen V., et al. Design and optimization of textures on the surface of crankpin bearing to improve lubrication efficiency and friction power loss (LE-FPL) of engine. Proceedings of the Institution of Mechanical Engineers, Part J: Journal of Engineering Tribology, 2020, https://doi.org/10.1177/1350650120942009.

[14] Nguyen V., Wu Z., Le V. Optimization of crankpin bearing lubrication under dynamic loading considering effect of micro asperity contact. Industrial Lubrication and Tribology, Vol. 72, 2020, p. 1173-1179.

[15] Jiao R., Nguyen V., et al. Optimal design of micro-dimples on crankpin bearing surface for ameliorating engine's lubrication and friction. Industrial Lubrication and Tribology, 2020, https://doi.org/10.1108/ILT-04-2020-0152. 